\title{
Peer and Vicarious Framing, Problematization, and Situated Learning in Online Professional Masters Courses
}

\author{
Susan Gasson \\ Drexel University \\ sgasson@drexel.edu
}

\author{
Jonan Donaldson \\ Drexel University \\ jpd322@drexel.edu
}

\begin{abstract}
This paper presents a socio-cognitive view of collaborative knowledge-building in situated learning. We explore the modes of interaction encountered in an online, professionally-oriented graduate Project Management course, to understand how we can provide the conditions for vicarious and peer knowledge-building that situates learning within the context, cultural identity, and practices of realworld, professional work environments.
\end{abstract}

\section{Introduction}

As so much of our day to day life shifts online, the emergence of online education platforms as the transport medium for remote education has become the norm. Online learning environments provide some efficiency gains, consumer flexibility and the potential to reach a wider audience. But online learning environments present challenges for the acquisition of professional knowledge and skills - the ability to apply knowledge or methods gained in one context to another. Professional domain courses, such as Project Management, require the student to reflect on their experience and to develop contingency models of how to act that are based on the norms and expectations of a professional community of practice. But many students lack the experience to apply to this task, or the ability to understand what they need to learn and how to make sense of alternate courses of action without recourse to the application domain. It has been proposed that professional skills that are developed in one context (for example a classroom) then applied to a different context (for example, professional project management) - can be developed through Web 2.0 tools: blogs, WIKIs, discussion boards, and multimedia case analyses that allow students to explore and evaluate knowledge provided by experienced professional practitioners. But these tools fail to support the joint practices and shared cultural understandings that lead to the construction of professional group identity and membership [9]. Situated learning involves the formative evaluation of ideas from professional peers as well as course instructors [11], reflective practice in a social context [15], and vicarious learning through social interaction [16]. After a brief period of research interest in the late 1990s, an interest in the social context of learning appears to have been largely subsumed to the study of technology delivery platforms. We have little understanding of how to design online learning courses for the type of situated learning relevant to professional domains. This paper reports on an exploratory study to address the overarching research question:

How can we engage students effectively in situated learning processes that reflect the social identity, cultural values, and practices of professional communities of practice in online, Masters degree courses?

\section{Framing situated learning}

The ability to select from, and to share cognitive frames is central to situated professional practice. Peripheral participants become core members of a professional workgroup through a form of apprenticeship, in which they are introduced to the sociocultural norms and expectations that guide definitions of "professional" (and, indeed "practice") [9]. Cognitive frames provide a performative framework and script for action in similar situations [7]. The constructivist learning - learning by doing that is involved in peripheral participation allows newcomers to jointly enact organizational frameworks for action, providing them with a shared, performative frame that guides future practice [17] and to reflect on the material-discursive practices that constitute "professionalism" in organizational work, guiding identity [9]. But situated learning requires a context that can be related to the context of organizational practice sufficiently well to allow students to develop context- and community specific frameworks for action. 
Vicarious learning communicates context in the form of case studies, analogies, and "war stories". In online learning environments, it can be accomplished by the analysis and problematization of case studies under the guidance of an instructor, or by peerlearning whole accomplishing a shared task, or engaging in a problem-directed discussion [1, 2]. Problematization, the framing and structuring of situational elements to present specific types or aspects of a problem, is understood to be a key part of developing strategies for professional practice but is also susceptible to a variety of social constructions that may make it less helpful in developing transferable skills [12]. The acquisition of transferable skills that are valued in professional practice requires contextualization, provided by "thought leaders" who shape community frames with narratives, analogies, and problematizations that fit with the context of professional practice [5]. We therefore examine the role of problematization in the construction of transferable frameworks for action.

Finally, social engagement with a community of practice (or inquiry) is critical in constructing shared frameworks for action and problematization. Learning occurs in the space between an individual and the community of practice [8] Constructivist approaches to education focus on individual cycles of knowledge assimilation, while situated learning focuses on advancing community knowledge, with individual learning as a by-product [14].. Community knowledge-building requires a strong focus on ideas and the situated context in which they are applied to be of value. This can be provided by course materials that scaffold the vicarious learning experience for students [1, 2], and through cycles of interaction between students, their peer learning community members, and forms of problematization that reflect "real ideas, authentic problems" [13]. Becoming a professional practitioner involves legitimate peripheral participation, through which the individual learner identifies themselves as a member of a professional community, and becomes enculturated in the norms and values of that community, as well as its practices $[8,9]$.

In light of the concepts discussed here, we defined three detailed research questions:

RQ1. How can we define an effective set of guiding principles for vicarious learning and peer-community knowledge building?

RQ2. How do students in professionally-oriented, online MS courses collectively construct and understand course-related knowledge?

RQ3. How can community knowledge be contextualized for professional relevance?

\section{Method}

This paper presents an exploratory study of elements that enable effective peer-learning, to produce transferable skills, knowledge, and to develop students' metacognitive abilities. We present our analysis of (guided) discussions between 26 students engaged in an online Information Systems Project Management course. This course was selected for our initial sample, as it provides a good example of professional practice in a specialist context (technical systems development), combining this with the need to learn the "soft" skills that appear to be problematic in online learning environments. It included a majority of students with experience of working on IS development projects, so students possessed a relatively high degree of professional experience that they could share.

The main stream of course instruction was provided by lectures, instructor podcasts, and worked examples, which guided students through an incremental series of learning-by-doing assignments, which evaluated students' ability to apply skills and knowledge about project planning to a case study situation. The discussions analyzed in this paper constituted a secondary stream of learning, to supplement these practical skills with situational and professional community knowledge about how to manage software development projects.

To understand individual vs. collective knowledge building behaviors of students, we employed a grounded theory analysis of student discussion post behaviors [6]. We performed three rounds of coding, starting with a set of a priori codes derived from a previous grounded theory study by the first author [5], as our topic guide. Development of a topic guide acknowledges the influence of other authors and examines our own pre-understanding of the research problem to clarify an appropriate focus for initial data collection and analysis [5]. Each data set was coded by the second author in consultation with the first author, to discuss and validate categories. We employed a rich memoing process to collect and discuss both processual and analytic insights. Comparing the rationale for differences in coding across researchers is more effective in developing a set of theoretical categories for grounded theory than the form of co-coder comparison used in studies that adopt a pre-defined coding scheme [5]. We focused our initial selective coding around what we had noted about how students interacted, refining the initial categories of their role in debate development, and introducing categories to capture their social discourse behaviors, and their knowledge-building discourse behaviors, as they 
synthesized, developed, or disagreed with the ideas of others. This led to a set of selective codes that emerged around the core category of idea framing: how students framed, reframed, problematized, or agreed frames for that week's topic, as sociallysituated framing. At this point, we returned to the literature on framing, in particular the work of Goffman [7], relating this to work on social cognition in learning environments [14], to understand the observed behaviors. Theoretical sampling compared categories of socio-cognitive behaviors and patterns in community debate across weeks of discussion each of which dealt with a separate professional topic or problem for discussion. We developed our current set of meta-categories and our substantive model of how these are related after the first 4-5 weeks' of data analysis, but continued the constant comparison across all weeks to ensure theoretical saturation [3].

\section{Findings}

\subsection{Guiding principles for vicarious learning and community knowledge building}

The guiding principles emphasized by Scardamalia [13] were adopted for this course scaffold, which provided procedural guidelines for discussion, reinforced by an explicit reward structure (grading rubric).

4.1.1 Procedural guidelines. Under the heading Participation In Class Discussions, students were provided with procedural guidelines for how to participate in collective knowledge building, as follows:

Reflective discussion is a critical part of learningby-doing, as is the critical thinking that professional skills require. I expect discussions to be equivalent in quality to the type of analysis that you might produce for your manager if he or she asked you to investigate how to do something new. You should prepare assigned cases and readings in advance, research that week's topic and discuss the questions/topics set for each (and every) week with informed insight.

Students were instructed to post an individual analysis of the topic or case study that addressed the questions posted on the discussion board, on or before Thursday of each week (Mon-Sun). Questions were structured to be exploratory but also directed to specific situations or skills [4]. They were required to follow this up with at least two reflective discussions of the posts of other students, as follows:

Fri-Sun: Read and respond to (discuss or critique) at least two of your fellow-students' analyses. Follow up with people who have responded to your analysis - and those who have responded to your critique of their analysis - in interactive debate that reaches a consensus on how to deal with the topic for that week.

The graph shown in Figure 1 provides a summary of discussion posts over the 10 weeks of the course.

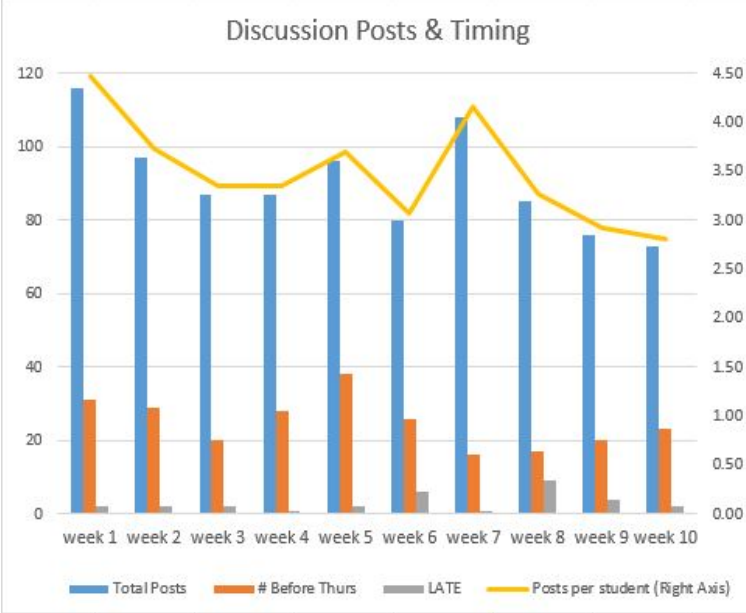

Figure 1. Discussion post totals and timing

The majority of posts were made in good time and were focused on the situation under discussion. Some topics generated more debate than others. In week 8, when students discussed what makes for a successful adaptive project, the debate was still raging at the week-end, as students returned to read and respond to posts for 2-3 days following. $10 \%$ of week 8's messages were posted after the weekend.

Table 1. Discussion reward-structure (extract)

\begin{tabular}{|l|l|}
\hline$A+$ (MVP) & $\begin{array}{l}\text { Consistently participates, debates } \\
\text { points, and provides unique insights } \\
\text { which significantly advance the } \\
\text { understanding of others. Provides } \\
\text { resources and interpretations of topic } \\
\text { from research and reading. Frequently } \\
\text { interacts with other students in debate, } \\
\text { adding to, complicating, and extending } \\
\text { their insights multiple times. }\end{array}$ \\
\hline $\begin{array}{l}\text { S (1st } \\
\text { Stringer) }\end{array}$ & $\begin{array}{l}\text { Consistently participates by attempting } \\
\text { to explain relevant issues, providing } \\
\text { insights and resources from own } \\
\text { experience or research. Often interacts } \\
\text { with other students in debate (at least } \\
\text { twice in each week), and complicates } \\
\text { the ideas of others at least once. }\end{array}$ \\
\hline $\begin{array}{l}\text { "I have no experience, so I have } \\
\text { Violet) }\end{array}$ & $\begin{array}{l}\text { nothing to say. Here's a summary of } \\
\text { something that I read" (with attribution } \\
\text { and your own summary). Responds to } \\
\text { others with additional information }\end{array}$ \\
\hline C (Lookout) & $\begin{array}{l}\text { Good observer, participates at end of } \\
\text { discussion, usually only contractually } \\
\text { with a few comments on the thought of } \\
\text { others ("that's a good idea, Jake!"). }\end{array}$ \\
\hline
\end{tabular}


4.1.2 Explicit reward structure. Students were provided with an explicit reward-structure for course participation. This participation framework was developed over multiple prior studies, which have verified that this achieves increased peer-interaction and posting of "war stories" that may lead to vicarious-learning [16]. The rubric, an extract from which is given in Table 1 , rewards specific participation behaviors, by associating with a higher grade behaviors such as "provides unique insights which significantly advance the understanding of others," or "complicating, and extending [peer student] insights.” It associates behaviors that are thought to undermine effective problematization or peer-knowledge construction with a lower grade.

4.1.3 The role of early, formative feedback. Early and explanatory instructor feedback was found to be a critical part of the scaffold for community knowledge-building. Students were provided with the following advice: "War stories and reflections on your own experience - in class, other courses, or in your company- are appreciated! Experience does not need to relate specifically to software projects project management is project management, regardless of the product." But in weeks 1 and 2, students were still unsure of how to post, or what content constituted "discussion."
Rapid instructor feedback in these weeks asked students to illustrate the point they were making with explicit stories, examples, and analogies, in order to "make it real." Students were encouraged to explain the situation in which they had experienced issues, and to explain how the situation affected things. From week 3 onwards, following two rounds of rapid formative feedback, student posts tended to become more informative, interactive, and situated in the context and contingencies of the problems discussed.

\subsection{Individual framing \& problematization}

We then performed a second round of coding, to identify socio-cognitive behaviors that indicated interactions based on socially-situated knowledge construction. This resulted in a set of interaction categories based on social discourse and knowledgebuilding interactions. As we engaged in comparison of student interaction behaviors across weeklysamples, sub-categories emerged that were related to how students framed the topic, or problematized the frames employed by others. These are summarized in Table 2. These codes allowed us to explore both individual attempts to understand issues related to each week's topic and how individuals interacted with other community members to achieve a collaborative process of understanding.

Table 2. Explanation of Advanced Framing Behaviors

\begin{tabular}{|c|c|c|}
\hline Behavior & in vivo example & Description \\
\hline $\begin{array}{l}\text { implicit } \\
\text { framing }\end{array}$ & $\begin{array}{l}\text { Prior to formal kick-off I would attempt to } \\
\text { collect as much of the project context as I } \\
\text { could and review it to fine-tune the approach. } \\
\text { From our prior conversations, I do not think } \\
\text { one size fits all and requirements solicitation is } \\
\text { no different. In some instances, the } \\
\text { information that I would be attempting to } \\
\text { retrieve beforehand simply may not exist, be } \\
\text { loosely defined, may be requirements from } \\
\text { one viewpoint in the organization, may } \\
\text { describe a potential solution instead of the } \\
\text { root problem(s) we are trying to solve or a } \\
\text { mixture of the above. }\end{array}$ & $\begin{array}{l}\text { Implicit framing involves discussing aspects of } \\
\text { the topic, process, or problem set by the } \\
\text { instructor for that week. Three related questions } \\
\text { would relate the topic to course materials and } \\
\text { readings, to provide students with an explicit } \\
\text { scaffold for the week's discussion - students } \\
\text { generally answered one to all of these, in their } \\
\text { initial framing attempt. Students would explore } \\
\text { the questions through the lens of personal } \\
\text { experience or readings and materials from the } \\
\text { course. Almost all students would attempt this, in } \\
\text { any week. }\end{array}$ \\
\hline $\begin{array}{l}\text { explicit } \\
\text { framing }\end{array}$ & $\begin{array}{l}\text { Ensuring that all stakeholders fully understand } \\
\text { the requirements and outcomes is essential.. } \\
\text {. However, when working with diverse groups } \\
\text { of stakeholders the challenge becomes the } \\
\text { requirements needed by each group can differ } \\
\text { substantially from another group. }\end{array}$ & $\begin{array}{l}\text { Frame definition involves proposing or creating a } \\
\text { new perspective/lens through which to } \\
\text { understand a concept, process, or problem. }\end{array}$ \\
\hline $\begin{array}{l}\text { frame } \\
\text { confirmation } \\
\text { / reiteration }\end{array}$ & $\begin{array}{l}\text { You are correct when you say use-case will } \\
\text { guide us in deciding what function point } \\
\text { needed. It also simple enough to minimize the } \\
\text { overhead of the measurement process as well } \\
\text { as a consistent measure among various } \\
\text { projects and organizations. }\end{array}$ & $\begin{array}{l}\text { Frame confirmation/reiteration repeats aspects of } \\
\text { the frame already in play, often through stories } \\
\text { which illustrate an aspect of the frame. Because } \\
\text { stories are also used by frame elaborators, it is } \\
\text { important to identify the purpose of the story. } \\
\text { Frame confirmers may also reiterate or } \\
\text { paraphrase what has been already said }\end{array}$ \\
\hline
\end{tabular}


Table 2 (continued). Explanation of Advanced Framing Behaviors

\begin{tabular}{|c|c|c|}
\hline Behavior & in vivo example & Description \\
\hline $\begin{array}{l}\text { frame } \\
\text { elaboration }\end{array}$ & $\begin{array}{l}\text { I wanted to take your point further regard the } \\
\text { last bullet point in Q1 where you mention } \\
\text { about stakeholder's role, and commitment to } \\
\text { the overall impact on the project. In many } \\
\text { cases the culture of the organization and } \\
\text { commitment to the project from the top can } \\
\text { influence the relationship between business } \\
\text { management and project mgmt. }\end{array}$ & $\begin{array}{l}\text { Frame elaboration builds on the existing frame, } \\
\text { often through stories (but only when the story } \\
\text { adds something new). Because stories are also } \\
\text { used by frame confirmers, it is important to } \\
\text { identify the purpose of the story. Frame } \\
\text { elaborators may also describe in greater detail } \\
\text { aspects of what has already been said }\end{array}$ \\
\hline $\begin{array}{l}\text { questioning } \\
\text { the frame }\end{array}$ & $\begin{array}{l}\text { Stakeholders not being taken seriously is an } \\
\text { issue I have not heard of before. Do you have } \\
\text { any war stories about it? }\end{array}$ & $\begin{array}{l}\text { Questioning the frame points to problematic } \\
\text { aspects of the frame, or to the underlying } \\
\text { assumptions of the frame. }\end{array}$ \\
\hline $\begin{array}{l}\text { breaking } \\
\text { the frame }\end{array}$ & $\begin{array}{l}\text { I wonder, though, given the complexity of } \\
\text { systems that we are developing today, } \\
\text { whether it is possible to fully understand } \\
\text { project scope }\end{array}$ & $\begin{array}{l}\text { Breaking the frame involves rejection of a core } \\
\text { aspect or underlying assumption of the frame } \\
\text { currently in frame. }\end{array}$ \\
\hline $\begin{array}{l}\text { frame } \\
\text { revision }\end{array}$ & $\begin{array}{l}\text { I think what I'm trying to say with all of this is } \\
\text { that you should consider more optimistic time } \\
\text { estimates if you attempt to use agile } \\
\text { methodologies. }\end{array}$ & $\begin{array}{l}\text { Frame revision is a form of reframing which } \\
\text { involves changing aspects of the frame (minor or } \\
\text { major changes), but keeps a significant portion of } \\
\text { the original frame intact. }\end{array}$ \\
\hline $\begin{array}{l}\text { new frame } \\
\text { proposal }\end{array}$ & $\begin{array}{l}\text { My grandfather had a wonderful way of } \\
\text { describing how the Allies beat the Axis in } \\
\text { World War II. It was because of the } \\
\text { intervention of the Americans, who, according } \\
\text { to him, excelled at organized chaos. I believe } \\
\text { this is also a quality that one is apt to find in a } \\
\text { good project manager. }\end{array}$ & $\begin{array}{l}\text { New frame proposal is a form of reframing which } \\
\text { involves rejection of a frame which was } \\
\text { previously in play, while proposing an alternative } \\
\text { frame. The new frame may include some aspects } \\
\text { of the frame previously in play, but rejects a } \\
\text { significant portion such that the new frame bears } \\
\text { little resemblance to the previous frame. }\end{array}$ \\
\hline
\end{tabular}

Table 3. Frequency of Framing Behaviors

\begin{tabular}{|c|c|c|c|c|c|c|c|c|c|c|c|c|c|c|c|c|c|c|c|c|c|c|c|c|c|c|c|c|}
\hline Student & $\mathrm{S} 1$ & S2 & S3 & S4 & S5 & S6 & S7 & S8 & S9 & S10 & S11 & S12 & S13 S & S14 & S15 & S16 & S17 & S18 & S19 & $S 20 S$ & S21 & S22 S & S23 & S24 & S25 & S26 & S27 & TOT. \\
\hline $\begin{array}{l}\text { Implicit } \\
\text { Framing }\end{array}$ & 10 & 10 & 9 & 10 & 9 & 10 & 10 & 7 & 10 & 10 & 10 & 10 & 10 & 10 & 10 & 10 & 10 & 10 & 10 & 10 & 6 & 10 & 10 & 6 & 10 & 10 & 1 & 248 \\
\hline $\begin{array}{l}\text { Explicit } \\
\text { Framing }\end{array}$ & 1 & 0 & 1 & 1 & 1 & 0 & 1 & 0 & 0 & 0 & 0 & 0 & 1 & 0 & 0 & 0 & 0 & 0 & 1 & 1 & 0 & 0 & 0 & 0 & 0 & 0 & 0 & 16 \\
\hline $\begin{array}{l}\text { Frame } \\
\text { Reiteration/ } \\
\text { Confirmation }\end{array}$ & 2 & 0 & 1 & 2 & 3 & 0 & 2 & 0 & 5 & 5 & 2 & 4 & 5 & 0 & 0 & 5 & 0 & 3 & 8 & 2 & 1 & 2 & 3 & 0 & 2 & 1 & 0 & 116 \\
\hline $\begin{array}{l}\text { Frame } \\
\text { Elaboration }\end{array}$ & 1 & 2 & 0 & 6 & 2 & 3 & 8 & 0 & 5 & 8 & 1 & 2 & 1 & 0 & 3 & 2 & 0 & 0 & 3 & 2 & 0 & 2 & 2 & 1 & 2 & 0 & 0 & 112 \\
\hline $\begin{array}{l}\text { Rejecting } \\
\text { others' } \\
\text { Reframing or } \\
\text { Problematizing }\end{array}$ & 0 & 0 & 0 & 0 & 0 & 0 & 1 & 0 & 0 & 0 & 0 & 0 & 1 & 0 & 1 & 1 & 0 & 0 & 0 & 1 & 0 & 0 & 0 & 0 & 0 & 0 & 0 & 10 \\
\hline $\begin{array}{l}\text { Questioning } \\
\text { the Frame }\end{array}$ & 2 & 0 & 2 & 0 & 0 & 1 & 5 & 0 & 1 & 0 & 0 & 1 & 2 & 2 & 1 & 2 & 1 & 1 & 3 & 0 & 0 & 1 & 4 & 0 & 3 & 1 & 0 & 66 \\
\hline $\begin{array}{l}\text { Breaking the } \\
\text { Frame }\end{array}$ & 0 & 0 & 0 & 0 & 0 & 0 & 2 & 0 & 0 & 0 & 0 & 1 & 0 & 0 & 0 & 0 & 0 & 0 & 0 & 2 & 0 & 1 & 0 & 0 & 1 & 0 & 0 & 14 \\
\hline $\begin{array}{l}\text { Frame } \\
\text { Revision }\end{array}$ & 1 & 1 & 0 & 1 & 0 & 0 & 2 & 0 & 0 & 1 & 0 & 0 & 0 & 0 & 1 & 1 & 0 & 0 & 2 & 1 & 0 & 2 & 0 & 0 & 1 & 0 & 0 & 28 \\
\hline $\begin{array}{l}\text { New Frame } \\
\text { Proposal }\end{array}$ & 0 & 0 & 0 & 0 & 0 & 0 & 0 & 0 & 0 & 0 & 0 & 0 & 0 & 0 & 1 & 0 & 0 & 0 & 0 & 0 & 0 & 2 & 0 & 0 & 2 & 0 & 0 & 10 \\
\hline TOTA & & 31 & 20 & 60 & 33 & 32 & 82 & 11 & 54 & 89 & 25 & 40 & 53 & 12 & 46 & 54 & 10 & 32 & 67 & 42 & 24 & 43 & 60 & 5 & 47 & 21 & 6 & 2478 \\
\hline
\end{tabular}


After coding all weeks' data using the three category schemas (role in debate development, social discourse, and knowledge-building discourse categories), we employed data visualizations to explore possible relationships between categories [10]. The initial visualizations were concerned with the relationships between the a priori categories and the two emergent framing categories exemplified in Table 2. When we examined individual student framing behaviors, we discovered that behaviors that radically develop or problematize the frames of others are rare. The most common behaviors were:

- Implicit framing (the initial attempt at understanding the topic);

- Frame reiteration or confirmation (me too! Posts);

- Frame elaboration (where a student would provide examples or analogies that explained how the frame might operate in detail.

Although not as common, questioning the frame was encouragingly frequent, leading students to have productive debates. These tended to take place in dyads, with other students joining in once they understood the point being made. Explicit framing the type of synthesis where a student intentionally summarized the collective frame for others, was rare, as was a new frame proposal. Many instances of frame questioning, rejection, or frame breaking were left hanging, with no alternatives proposed and no exploratory discussion to develop the frame. This may be due to the fragmented nature of a one-week discussion cycle, or it may be due to the poor structure afforded to the debate by Blackboard's discussion board format.

\subsection{Contextualization and social engagement with community thought-leaders}

We defined a "thought-leader" as someone whose ideas would be sought out by others. In the social network analysis of message read data, we would expect thought-leaders to have a high in-degree centrality. Although Blackboard provides few tools for analyzing interactions or student access data in real time, it does archive read and "hit" data for its discussion boards. This provided individual read access trace data, from which we produced a directional social network analysis (produced using Gephi) of who is reading whose posts. The resulting network, over the 10 weeks of the course, is shown in Figure 3. Nodes in the social network graph are sized in proportion to the popularity of posts (the in-degree centrality of the post's author). So the larger the disk representing each student, the more people read their posts. Edges are sized proportionately to the strength of connection between two students - the more frequently one student read another's posts, the thicker the connecting line between them. It can be seen that there was a core group of students whose posts were read regularly by other students. Of course, habits like posting early in the week tended to ensure a wider readership than posts made later in the week - students were pretty strategic in their posting habits. But this data is not the "Hit" count that records people floating past a post. It is taken from explicit read accesses, where someone made a deliberate choice to stop, open, and read a post.

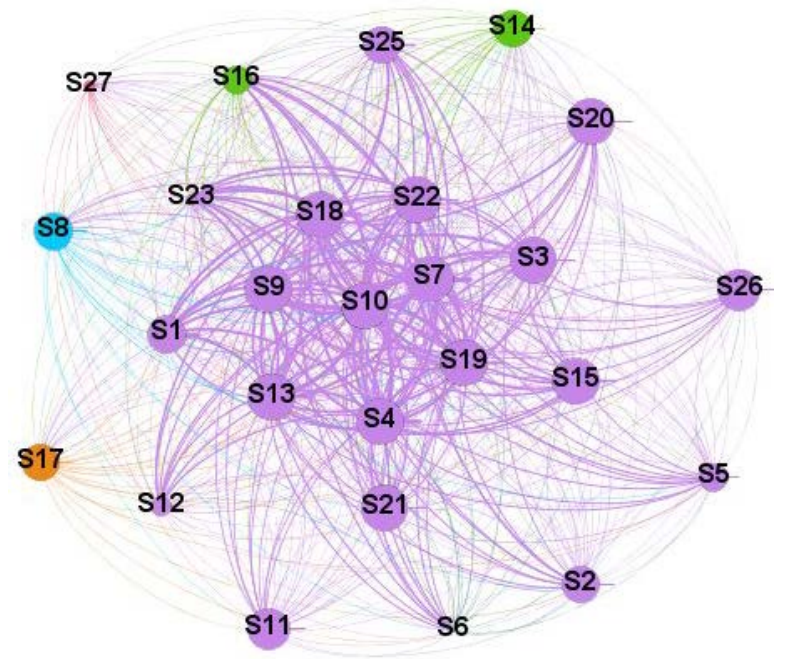

Figure 3. Social network analysis of who read whose posts

The degree of interactivity seen here is encouraging, validating the role of a reward structure that is designed to encourage collaborative debate and complexification of community frames. In fact, the social network shows a remarkably cohesive community, with almost no-one whose views are undervalued. There were no distinct cliques, possibly because of the proactive socialization engaged in by a core group of students (S4, S10, S13, S18, S19, S20, and S22). These students worked really hard at engaging less socially-interactive students, making the discussion much more inclusive than it might have otherwise been and setting the tone for wider debate.

Figure 4 shows a directional social network analysis (produced using Gephi) of direct interactions in the discussion board. The node size and font size indicate a student's degree centrality (connectedness to other community members). The colors indicate the degree of betweenness centrality: the redder the node, the more that student mediated between clusters of other students. The core group identified from post reads - S4, S10, S13, S18, S19, S20, and S22 - are still prominent, but not all so central to the flow of collaborative knowledge-building. 


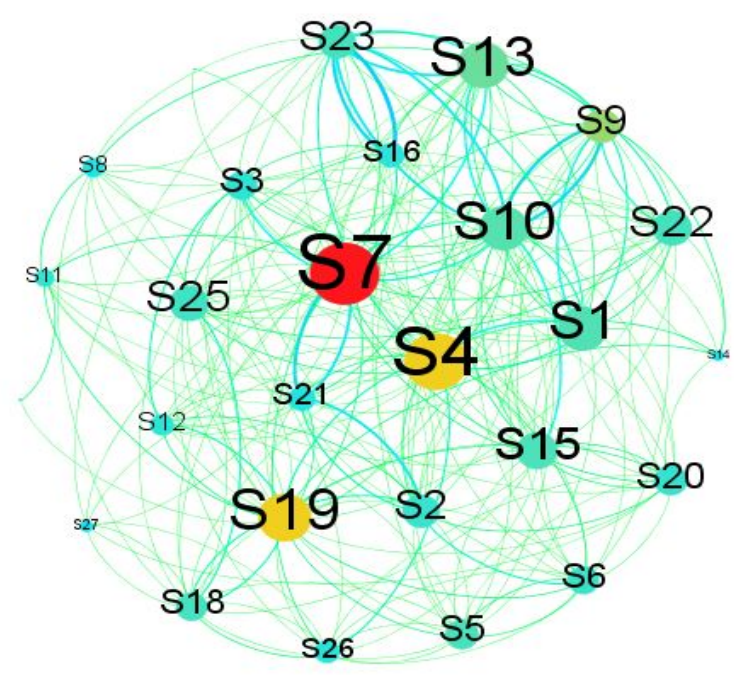

Figure 4. Social network analysis of who collaborated with whom in knowledge-building

So how did our framers and problematizers do, in terms of social network prominence? Table 4 summarizes the more advanced framing and problematization behaviors observed in our analysis, ranking students from the most engaged with framing and problematization (S7), to the least engaged (S27).

It is clear that there is some relationship between social recognition, both in terms of the thoughtleadership that leads others to seek out a student's posts, and the social facilitation that leads others to engage a student in constructive knowledge-building. It is also noticeable that the three most active discussants were also social mediators; S4, S7, and S19 stood out in their efforts to mediate topics across discussion subthreads, ranging from how to deal with an incompetent boss, to how to manage projects according to the ACM code of ethics when the client wanted reports on every user activity. When we explored the behaviors of those who were central to the learning community social network, we found a strong link between social engagement and the more advanced framing behaviors, with the exception of S4 who tended to focus on social recognition for interesting perspectives, rather than problematization of others' frames. While this facilitated the discussion immensely, encouraging more reticent students to hazard a disagreement with the current frame, it did not in itself advance the construction of a shared model of the week's topic.

\subsection{Collective framing \& problematization}

We conceptualized the collective process as an interactive, socio-cognitive cycle. Students engaged in
Table 4. Frequency of Framing Behaviors (Percentage of total found, across 10 weeks)

\begin{tabular}{|l|c|c|c|}
\hline Student ID & $\begin{array}{c}\text { Explicit } \\
\text { Framing }\end{array}$ & $\begin{array}{c}\text { Frame } \\
\text { Problematization }\end{array}$ & $\begin{array}{c}\text { Reframing } \\
\text { Behavior }\end{array}$ \\
\hline S7 & $9.4 \%$ & $17.5 \%$ & $10.5 \%$ \\
\hline S19 & $9.4 \%$ & $7.5 \%$ & $10.5 \%$ \\
\hline S10 & $10.2 \%$ & $0.0 \%$ & $5.3 \%$ \\
\hline S9 & $7.9 \%$ & $2.5 \%$ & $0.0 \%$ \\
\hline S16 & $6.3 \%$ & $5.0 \%$ & $5.3 \%$ \\
\hline S25 & $3.1 \%$ & $10.0 \%$ & $15.8 \%$ \\
\hline S4 & $7.1 \%$ & $0.0 \%$ & $5.3 \%$ \\
\hline S13 & $6.3 \%$ & $5.0 \%$ & $0.0 \%$ \\
\hline S22 & $3.1 \%$ & $5.0 \%$ & $21.1 \%$ \\
\hline S20 & $4.7 \%$ & $5.0 \%$ & $5.3 \%$ \\
\hline$S 23$ & $3.9 \%$ & $10.0 \%$ & $0.0 \%$ \\
\hline$S 12$ & $4.7 \%$ & $5.0 \%$ & $0.0 \%$ \\
\hline$S 1$ & $3.1 \%$ & $5.0 \%$ & $5.3 \%$ \\
\hline$S 15$ & $3.1 \%$ & $2.5 \%$ & $10.5 \%$ \\
\hline$S 5$ & $4.7 \%$ & $0.0 \%$ & $0.0 \%$ \\
\hline$S 3$ & $1.6 \%$ & $5.0 \%$ & $0.0 \%$ \\
\hline$S 6$ & $2.4 \%$ & $2.5 \%$ & $0.0 \%$ \\
\hline$S 18$ & $2.4 \%$ & $2.5 \%$ & $0.0 \%$ \\
\hline$S 2$ & $1.6 \%$ & $0.0 \%$ & $5.3 \%$ \\
\hline$S 11$ & $2.4 \%$ & $0.0 \%$ & $0.0 \%$ \\
\hline$S 14$ & $0.0 \%$ & $5.0 \%$ & $0.0 \%$ \\
\hline$S 26$ & $0.8 \%$ & $2.5 \%$ & $0.0 \%$ \\
\hline$S 17$ & $0.0 \%$ & $2.5 \%$ & $0.0 \%$ \\
\hline$S 21$ & $0.8 \%$ & $0.0 \%$ & $0.0 \%$ \\
\hline$S 24$ & $0.8 \%$ & $0.0 \%$ & $0.0 \%$ \\
\hline$S 8$ & $0.0 \%$ & $0.0 \%$ & $0.0 \%$ \\
\hline$S 27$ & $0.0 \%$ & $0.0 \%$ & $0.0 \%$ \\
\hline
\end{tabular}

cycles of debate to build a collective understanding of the topic, with framing followed by confirmation or reiteration, followed by elaboration or problematization, followed by reframing. This cycle appears to start with an individual engaging in explicit framing. In Table 5, we present a sequence of examples in which students explicitly frame project management planning by contrasting agile or adaptive project planning with predictive project planning. We argue that these examples, which were interspersed with other, less self-aware contributions, demonstrate the type of metacognitive engagement with knowledge-building that is required to construct contextualized, real-world knowledge. Learners engaging in these processes are forced to think critically about the nature of the work they perform.

It appears that the incentive scheme, the description of discussion behaviors, and early instructor feedback to encourage development of stories, examples, and analogies, guide students towards advanced framing. 
Instances of problematizing the frame never precede framing, and reframing never precedes problematizing the frame. Framing is not always followed directly by problematizing. In the majority of the cases, framing was followed by frame confirmation or reiteration, or by frame elaboration. Since frame elaboration often raised as many questions as it clarified, frame elaboration was interpreted as straddling both framing and problematizing. In the cycle of debate shown in Table 5, explicit framing is followed by frame elaboration in which another student describes the differences between adaptive and predictive project planning in terms of impact on future iterations, and then frame reiteration. Framing, frame confirmation/ reiteration, and frame elaboration were often either accompanied by or conducted via the modalities of stories (and/or analogies) and linking. Instances of problematizing the frame were most often in the form of questioning the frame, and at a lesser frequency in the form of breaking the frame.

Two types of problematization were identified: proximal problematizing, where a student questioned the frame via, or in response to, another's frame elaboration, and radical problematizing, where a student breaks the frame (disagreeing radically with the perspectives of others and introducing a collective breakdown into community knowledge-building). As with framing, instances of problematizing the frame were often either conducted via or accompanied by stories or linking. In Table 5 we see radical problematizing in which a student breaks the frame by rejecting the binary of adaptive vs. predictive project planning. Instances of frame-problematization were often left hanging, without any responses or suggestions of how to reframe the issue. When reframing did occur, it took one of two forms: a revised frame, or the proposal of a new frame. As with problematization, reframing instances ranged from proximal reframing in the form of minor framerevision to radical reframing, where new or substantially different frames were proposed. Instances of reframing were often expressed through or followed by linking to other students' experiences, analogies, or stories. The same student who broke the initial collective frame subsequently engaged in radical reframing by proposing a new frame, that of organized chaos.

\section{Discussion: social and metacognitive engagement in collective knowledge-building}

From our grounded theory analysis, we have developed a substantive theory, which suggests that community framing may be most closely related to the role of thought-leaders in initiating explicit frames for the community, problematizing the frame may be
Table 5. In vivo examples of posts in a cycle of framing, problematization, and resolution

\begin{tabular}{|l|l|}
\hline $\begin{array}{l}\text { Framing } \\
\text { Process }\end{array}$ & Descriptive or in vivo examples \\
\hline $\begin{array}{l}\text { explicit } \\
\text { framing }\end{array}$ & $\begin{array}{l}\text { Depending on the type of system being } \\
\text { developed, I think that there are two } \\
\text { paths (followed by a description of agile } \\
\text { in contrast to predictive project planning) }\end{array}$ \\
\hline $\begin{array}{l}\text { frame } \\
\text { elaboration }\end{array}$ & $\begin{array}{l}\text { The major differences between adaptive } \\
\text { and predictive planning, adaptive } \\
\text { planning is to avoid any predicable } \\
\text { planning in future iterations and } \\
\text { predictive planning can be predicable, } \\
\text { speculative, in other words, anti-adaptive. }\end{array}$ \\
\hline $\begin{array}{l}\text { frame } \\
\text { reiteration }\end{array}$ & $\begin{array}{l}\text { adaptive planning doesn't necessarily } \\
\text { provide that future insight so it's more } \\
\text { difficult to plan to do work now to reduce } \\
\text { work in the future }\end{array}$ \\
\hline breaking the & $\begin{array}{l}\text { Whether or not any of the stages of } \\
\text { project planning have different time } \\
\text { horizons or are conceived of from } \\
\text { different perspectives, the nature of work } \\
\text { does not change. Certain tasks must be } \\
\text { accomplished in the pursuit of some } \\
\text { defined goal. }\end{array}$ \\
\hline proposal & $\begin{array}{l}\text { No process can presume a perfect } \\
\text { knowledge of all possible scenarios, no } \\
\text { matter how carefully planned something } \\
\text { is ... My grandfather had a wonderful way } \\
\text { of describing how the Allies beat the Axis } \\
\text { in World War II. It was because of the } \\
\text { intervention of the Americans, who, } \\
\text { according to him, excelled at organized } \\
\text { chaos. I believe this is also a quality that } \\
\text { one is apt to find in a good project mgr. }\end{array}$ \\
\hline
\end{tabular}

closely related to an understanding of the need to complicate community framing, and reframing may come about as the result of social or socio-cognitive community facilitation. Figure 5 depicts our substantive theory of the ways in which individual framing and problematization appear to feed into the collective construction of meaning. Participants in online discussions engage in cycles of framing, problematizing suggested frames, and reframing the ideas to produce a workable model of action for the community. We observed repeated patterns of interactive and framing behaviors, summarized in Figure 5, which contributed to these cycles of understanding. An initial frame suggested by one or more participants is elaborated and then contextualized by reference to the socio-cultural framework of practice in which it would be applied. This leads to participants questioning the frame, problematizing it by providing a structure for analysis that leads to a breakdown of the frame. The problematized situation is recontextualized by exploring the conditions under which the frame breaks down, to revise the frame and 
then to engage in radical reframing, as participants situate the revised frame in various contexts, and link the emerging revision to other participants' situated observations.
We observed that some framing cycles did not result in reframing, but petered out, indicating limited learning. How to manage that remains a matter for further research.

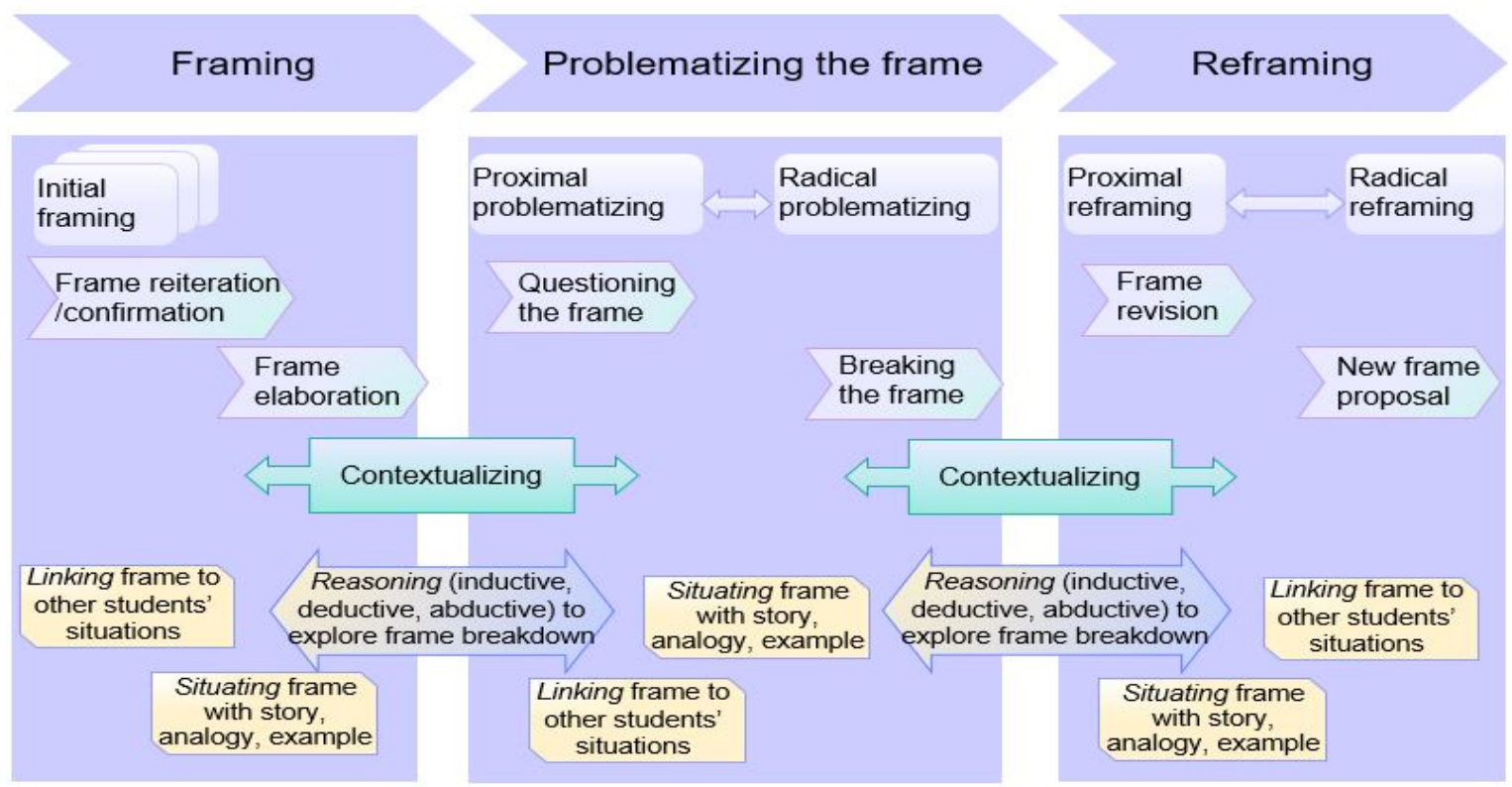

Figure 5. A substantive theory of how patterns of framing \& contextualization build into shared, situated professional knowledge

We have attempted to theorize patterns of interaction that develop shared frames of how to participate in a professional community of practice. In Goffman's [7] depiction of framing, the world that actors inhabit is physically-interactive. Symbolic meanings are constructed through observations of the real world that sensitize actors to the nature of action and its consequences. The mechanisms by which ideas are framed and understandings internalized depend on physical interactions - Schön's dialog with the context of action [15] - that are not available to participants in online communities. In the context of online courses, we have theorized that by introducing vicarious and peer-knowledge to supplement that of the instructor, we may provide a requisite variety of perspectives through which students can understand professional practice without "being there" in practice [17].

In designing this study, we asked three detailed questions, the answers to which are summarized here:

RQ1. How can we define an effective set of guiding principles for vicarious learning and peercommunity knowledge building? Section 4.1 provided the set of guiding principles and an explicit reward structure that we found effective in regulating peer-debate. We found that student engagement in peer-knowledge construction, and the development of students' ability to engage in vicarious learning depended on instructor awareness of the type of contributions that provided situated knowledge (using stories, analogies, and specific examples), coupled with early, formative feedback from the instructor.

RQ2. How do students in professionally-oriented, online MS courses collectively construct and understand course-related knowledge? We identified patterns of framing, contextualizing, and reasoning behaviors that underpin the construction of shared, situated knowledge. We identified patterns of peer-interaction and how frames are contextualized to provide an abstract understanding that can be related to various situations in collaborative discourse. Finally, we derived a substantive theory of how patterns of discourse \& contextualization build into shared, situated professional knowledge in a community of inquiry, shown in Figure 5.

RQ3. How can community knowledge be contextualized for professional relevance? Our substantive theory advances our understanding by relating the social cognitive processes underpinning the construction of situated knowledge to a proxy form of legitimate peripheral participation [9] that can be employed in an online community of inquiry, where access to the real-world locations with which a community of practice engages is not feasible. 


\section{Conclusions}

In this paper, we have presented the findings from a grounded theory study that explored the patterns of socially-situated learning required to educate and enculturate students as legitimate peripheral participants in professional practice [9]. Our findings suggest a substantive theory of how patterns of framing \& contextualization build into shared, situated professional knowledge. This study draws on prior work by the first author $[4,5]$ but should also be considered as part of a stream of research aimed at producing an emergent theory of how to support and scaffold online instruction, for professional Masters degree courses. A substantive theory is based on the constant comparison of findings across multiple data samples to explore common themes, relationships, and patterns in a specific situation [6]. Our theory is therefore transferable to similar contexts [3]. The contribution of this study is to advance our understanding of how to support professional, situated, knowledge construction in a community of inquiry by providing a socio-cognitive theory of how students frame, problematize, and reframe collective knowledge by means of contextualizations that provide a proxy form of legitimate peripheral participation in professional group identity and membership [8, 9]. These processes depend on experienced participants in the professional domain (in this case, software development projects) who act as thought-leaders and can contribute vicarious knowledge to this joint community process of sensemaking [17].

We plan to explore more courses that involve collective knowledge-building to explore if patterns of framing/problematization/reframing vary with different contexts of professional knowledge. This work will lead to improved design of evaluation tools and visualizations for online instruction that aid in identifying and supporting peer- and vicarious learning in professional, graduate-level courses.

\section{References}

[1] Cox, R., McKendree, J., Tobin, R., Lee, J., and Mayes, J.T., "Vicarious learning from dialogue and discourse: A controlled comparison", Instructional Science, 27, 1999, pp. 431-458.

[2] Dineen, F., Mayes, J.T., and Lee, J., "Vicarious learning through capturing task-directed discussions", Association for Learning Technology Journal, 7(3), 1999, pp. 33-43.

[3] Gasson, S., "Rigor In Grounded Theory Research: An Interpretive Perspective On Generating Theory From Qualitative Field Studies", in M. Whitman and A.
Woszczynski, (Eds.): Handbook for Information Systems Research, Idea Group Publishing, Hershey PA, 2003

[4] Gasson, S. and Waters, J., "How (not) to construct ALN course questions that encourage student participation in peer collaboration and knowledge construction", Hawaii Intl. Conference on System Sciences (HICSS-40), 2007

[5] Gasson, S. and Waters, J., "Using A Grounded Theory Approach To Study Online Collaboration Behaviors", European J. of Info. Systems, 22(1), 2013, pp. 95-118.

[6] Glaser, B.G. and Strauss, A.L., The Discovery of Grounded Theory, Aldine Publishing, New York, 1967.

[7] Goffman, E., Frame Analysis, Harper and Row, New York, NY, 1974.

[8] Lave, J., "Situating Learning In Communities of Practice", in L.B. Resnick, J.M. Levine, and S.D. Teasley, (Eds.): Perspectives on Socially Shared Cognition, American Psych. Assoc., Washington DC, 1991, pp. 63-82.

[9] Lave, J. and Wenger, E., Situated Learning: Legitimate Peripheral Participation, Cambridge University Press, Cambridge UK, 1991.

[10] Lempert, L.B., "Asking Questions of the Data: MemoWriting in the Grounded Theory Tradition", in A. Bryant and K. Charmaz, (Eds.): The Sage Handbook of Grounded Theory, Sage, Thousand Oaks Cal., 2007, pp. 245-264.

[11] McLaughlin, T. and Yan, Z., "Diverse delivery methods and strong psychological benefits: A review of online formative assessment", Journal of Computer Assisted Learning, 2017,

[12] Reiser, B.J., "Scaffolding complex learning: The mechanisms of structuring and problematizing student work", The Journal of the Learning Sciences, 13(3), 2004, pp. 273-304.

[13] Scardamalia, M., "Collective Cognitive Responsibility for the Advancement of Knowledge", in B. Smith, (ed.): Liberal education in a knowledge society, Open Court, Chicago, 2002, pp. 67-98.

[14] Scardamalia, M. and Bereiter, C., "Knowledge building: Theory, pedagogy, and technology", in K. Sawyer, (ed.): Cambridge Handbook of Learning Sciences, Cambridge Univ. Press, New York, 2006, pp. 97-118.

[15] Schön, D.A., Educating the Reflective Practitioner, Jossey-Bass, San Francisco, CA., 1987.

[16] Waters, J. and Gasson, S., "Supporting Reflective, Peer and Vicarious Learning in Online, Professional Graduate Courses", Hawaii Intl. Conference on System Sciences (HICSS-48), 4-8 Jan. 2015., 2015

[17] Weick, K.E., Making Sense of the Organization, Blackwell Scientific, Malden MA, 2001. 